Vanja Ferreira'

Cláudia Brito"

Margareth Portela"'

Claudia Escosteguy ${ }^{\text {IV }}$

Sheyla Lima"'

Programa de Controle da Tuberculose, Superintendência de Vigilância em Saúde, Secretaria de Estado de Saúde e Defesa Civil do Rio de Janeiro. Rio de Janeiro, RJ, Brasil

Programa de Pós-Graduação em Saúde Pública. Fundação Oswaldo Cruz (Fiocruz). Rio de Janeiro, RJ, Brasil

III Departamento de Administração e Planejamento em Saúde. Fiocruz. Rio de Janeiro, RJ, Brasil

Serviço de Epidemiologia. Hospital Federal dos Servidores do Estado do Rio de Janeiro. Rio de Janeiro, RJ, Brasil

Correspondence:

Margareth Portela

R. Leopoldo Bulhões 1480, sala 724

Manguinhos

21041-210 Rio de Janeiro, RJ, Brasil

E-mail: mportela@ensp.fiocruz.br

Received: 5/31/2009

Approved: 6/16/2010

Article available from: www.scielo.br/rsp

\section{DOTS in primary care units in the city of Rio de Janeiro, Southeastern Brazil}

\section{Implementação e resultados do DOTS em unidades básicas de saúde na cidade do Rio de Janeiro}

\begin{abstract}
OBJECTIVE: To describe the implantation and the effects of directly-observed treatment short course (DOTS) in primary health care units.

METHODS: Interviews were held with the staff of nine municipal health care units (MHU) that provided DOTS in Rio de Janeiro City, Southeastern Brazil, in 2004-2005. A dataset with records of all tuberculosis treatments beginning in 2004 in all municipal health care units was collected. Bivariate analyses and a multinomial model were applied to identify associations between treatment outcomes and demographic and treatment process variables, including being in DOTS or self-administered therapy (SAT).
\end{abstract}

RESULTS: From 4,598 tuberculosis cases treated in public health units administrated by the municipality, 1,118 (24.3\%) were with DOTS and 3,480 (75.7\%) with SAT. The odds of DOTS were higher among patients with age under 50 years, tuberculosis relapse and prior history of default or treatment failure. The odds of death were $52.0 \%$ higher among patients on DOTS as compared to SAT. DOTS modality including community health workers (CHWs) showed the highest treatment success rate. A reduction of $21.0 \%$ was observed in the odds of default (vs. cure) among patients on DOTS as compared to patients on SAT, and a reduction of $64.0 \%$ among patients on DOTS with CHWs as compared to those without CHWs.

CONCLUSIONS: Patients with a "low compliance profile" were more likely to be included in DOTS. This strategy improves the quality of care provided to tuberculosis patients, although the proposed goals were not achieved.

DESCRIPTORS: Tuberculosis, prevention \& control. Antitubercular Agents, supply \& distribution. Medication Adherence. Patient Dropouts. Treatment Outcome. Health Services. 


\section{RESUMO}

OBJETIVO: Descrever a implantação e os efeitos do directly-observed treatment short course (DOTS) em centros municipais de saúde.

MÉTODOS: Foram realizadas entrevistas com profissionais dos nove centros municipais de saúde que ofereciam DOTS no Rio de Janeiro, RJ, em 2004-2005. Foram coletados os dados de todos os centros municipais de saúde da cidade sobre os tratamentos de tuberculose iniciados em 2004. Análises bivariadas e modelo multinomial foram aplicados para identificar associações entre resultados do tratamento e variáveis demográficas e relativas ao processo de tratamento, incluindo estar em DOTS ou terapia auto-administrada (SAT).

RESULTADOS: Dos 4.598 casos de tuberculose tratados, 1.118 (24,3\%) utilizaram DOTS e $3.480(75,7 \%)$, SAT. As chances de uso de DOTS foram maiores entre pacientes com menos de 50 anos, recidiva de tuberculose, história prévia de abandono ou falência de tratamento. As chances de morte foram $52,0 \%$ maiores entre pacientes em DOTS comparados àqueles em SAT. A modalidade de tratamento com maior sucesso foi DOTS com agentes comunitários de saúde. Foi observada redução de 21,0\% na razão de chances de abandono (vs. cura) entre pacientes em DOTS, comparados a pacientes em SAT, e redução de $64,0 \%$ entre pacientes em DOTS com ACS, comparados àqueles sem.

CONCLUSÕES: Pacientes com perfil de menor adesão ao tratamento tenderam a ser incluídos em DOTS. Essa estratégia melhora a qualidade da atenção provida a pacientes com tuberculose, ainda que metas propostas não tenham sido atingidas.

DESCRITORES: Tuberculose, prevenção \& controle. Antituberculosos, provisão \& distribuição. Adesão à Medicação. Pacientes Desistentes do Tratamento. Resultado de Tratamento. Serviços de Saúde.

\section{INTRODUCTION}

According to the World Health Organization (WHO), Brazil ranks 18th among 22 countries in tuberculosis (TB) cases accounting for $80.0 \%$ of all cases worldwide. Data from Brazil's National Notifiable Diseases Database (SINAN) for the year 2004 show a national reporting rate of 45.3 cases per 100,000 inhabitants.

Given the relevance of TB in Brazil, in 1998, the Brazilian Ministry of Health launched the National Plan to Fight Tuberculosis, which proposed the implementation of the Directly Observed Treatment Short-Course (DOTS) Strategy, tuberculosis control programs (TCP) in $100.0 \%$ of the country's municipalities, adequate treatment of $100.0 \%$ of the diagnosed cases, cure of at least $85.0 \%$ of these cases, and a default rate of less than 5.0\%. Brazil endorsed the first WHO Global DOTS Expansion Plan in 2000 and TB was declared a national priority in 2004. An action plan was drafted for 2004-2007, defining the 315 municipalities with $70.0 \%$ of the country's TB cases as the priority for strengthening disease control measures and expanding supervised TB treatment to include $100.0 \%$ of health units in these municipalities.

The state of Rio de Janeiro, Southeastern Brazil, has the highest annual TB incidence rate in Brazil. In 2004, 15,755 cases of TB were reported in the state, accounting for approximately $15.0 \%$ of all cases in Brazil. Rio de Janeiro has also the highest TB mortality rate in Brazil, i.e., 6.0 per 100,000 inhabitants in 2004 , nearly twice the national rate. It also accounted for $42.0 \%$ of multidrugresistant tuberculosis (MDR-TB) cases in the Southeast in 2000-2003, the Brazilian region with the highest proportion of cases in the country $(66.4 \%) .{ }^{3}$ Cure rate was $68.2 \%$ and default rate was $16.3 \%$ in 2004 . Of all cases reported in the state of Rio de Janeiro, $54.0 \%$ lived in the city of Rio de Janeiro.

According to the literature, ${ }^{12,16,18,20,24,25}$ DOTS with enablers showed a treatment completion rate of 86.0

a Secretaria de Estado de Saúde do Rio de Janeiro. Boletim Informativo do Programa de Controle da Tuberculose do Estado do Rio de Janeiro. Rio de Janeiro; 2005. 
to $96.5 \%$ and a relapse rate of 0.0 to $11.5 \%$. Without treatment regularity, enablers and incentives, treatment completion rate ranged from $85.0 \%$ to $87.6 \%$ and relapse rate from $0.8 \%$ to $4.9 \%$. In addition, nonsupervised strategies were associated to treatment completion rates ranging from $41.9 \%$ to $82.0 \%$ and relapse rates from $2.1 \%$ to $4.5 \%$. DOTS was more cost-effective than self-administered treatment (SAT), particularly when epidemiological indicators point to high default, relapse, multi-resistant TB, and mortality rates. ${ }^{2,3,5,6,8,9,13,21}$

Castelo Filho et $\mathrm{al}^{3}$ highlight that the impact of the implementation of DOTS strategy under different conditions and at various levels on TB treatment outcomes is due more to the set of organizational measures as a whole than direct observation of dose-taking. Supervised treatment should be applied with creative recommendations adjusted to Brazilian conditions, contemplating the country's diversity, especially in large cities, which have more than $80.0 \%$ of all TB cases in Brazil.

The various strategies to expand the National Tuberculosis Control Plan to all Brazilian municipalities also include the expansion and consolidation of the Brazilian Ministry of Health Community Health Workers (CHW) Program and the Family Health Program (FHP) in partnership with local governments. ${ }^{b}$ FHP coverage in the state of Rio de Janeiro was $24.0 \%$ in 2004 and $8.0 \%$ in the metropolitan area I (accounting for $76.0 \%$ of TB cases in the state). ${ }^{\mathrm{a}}$

DOTS implantation in the city of Rio de Janeiro began with a pilot project in 1999, funded by the Brazilian Ministry of Health with resources from the Tuberculosis Emergency Plan. Expansion to other locations was based on epidemiological, operational, and geographic criteria. The local Tuberculosis Control Program (TCP) contacted selected primary care services and held meetings with their managers and providers. Informative material was developed and distributed to TCP teams and patients. DOTS trainings were offered to TCP teams, and material focused on treatment data collection was developed and distributed to health units. Spaces were rebuilt or adapted, and equipment, supplies and human resources were provided to the units.

Nine units of 32 municipal health centers providing TCP offered DOTS to their patients in 2004-2005. The DOTS strategy was not exclusively provided and patients could choose SAT.

DOTS teams in municipal health centers consisted mainly of a physician, a nurse and a nursing assistant. Of the nine municipal health centers with DOTS, one included a $\mathrm{CHW}$ in the team selected among young residents of Rocinha slum, and trained on TB, DOTS, and FHP. Following the Brazilian guidelines for TB treatment with only three drugs, patients were treated with a directly observed six-month regimen consisting of daily rifampin, isoniazid and pyrazinamide (RHZ) for two months, followed by four months of twiceweekly rifampin and isoniazid (2RHZ/4R2H2). The coverage of DOTS in the city of Rio de Janeiro was $24.3 \%$ in 2004 .

The objective of the present study was to describe DOTS implementation and its impact on primary care services.

\section{METHODS}

Descriptive study with managers and TCP health providers carried out in primary care units with DOTS in the city of Rio de Janeiro. The study analyzed epidemiological secondary data of all primary care units providing TCP.

The heads of the local TCP were interviewed and general information about DOTS implementation in the city and the nine health units already providing DOTS were collected in August 2005.

Directors and health providers in charge of DOTS in the nine health units were also interviewed from April to July 2006 to characterize their structure and strategies. DOTS was implanted not as an exclusive treatment modality, but as an alternative to SAT. DOTS was exclusively offered in the community and monitored by CHWs.

Evaluation of treatment outcomes was based on TB records from all primary care units with or without DOTS. The original dataset consisted of 5,984 records from the Tuberculosis Case and Treatment Registry Database submitted to the local TBP including all treatments starting from January 1 to December 31, 2004. TB treatment provided in hospitals and maternity wards (1,066 cases) were excluded and only treatment provided in primary care units managed by the Health Department of the City of Rio de Janeiro were included. Entries with "change of diagnosis" (71 cases) or "transfer" (223 cases) were also excluded as well as those that did not include data specifically reporting DOTS (26 cases). There were a total 4,598 records of TB treatments, which were evaluated as to the adequacy of the treatment regimen and observed outcome, considering mainly the roles played by DOTS and $\mathrm{CHW}$. These roles were identified by a variable created by the local TCP and added to the Tuberculosis Case and Treatment Registry Database.

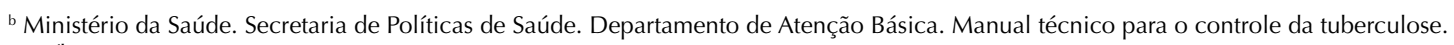
Brasília, DF; 2002. 
The independent variables were indicators of receiving DOTS and its specific strategy of involving CHWs. Other independent variables included: (1) treatment adequacy/inadequacy (according to the Brazilian Ministry of Health treatment guidelines); (2) treatment outcome (both confirmed and unconfirmed cures were classified as cures); (3) treatments type (initial, postrelapse, post-default, and post-failure); and (4) form of TB and information on HIV infection.

Explorations were developed to identify patterns for patient inclusion in DOTS, as well as differences DOTS made in health care process.

Bivariate analyses were performed to assess any associations between treatment outcomes (cure, default, death, failure, and unknown) and patient and processof-care characteristics. A multinomial model was used to identify the independent effects of the target explanatory variables on outcomes compared to cure. For the statistical analyses SUDAAM software version $\mathrm{SAS}^{\circledR}$ was used to deal with clustering of records in a single health unit.

The study was approved by the Research Ethics Committee of the Fundação Oswaldo Cruz National School of Public Health (ENSP-FIOCRUZ). All interviews were conducted after participants signed a free informed consent form.

\section{RESULTS}

Three of the nine primary care units providing DOTS had implemented it less than three years previous to the study and six of them more than three years before. Three units were open for up to 49 hours a week, were staffed with fewer than 100 people, and provided up to 8,000 medical consultations per month. Five units were open from 50 to 54 hours a week, had from 101 to 200 staff people, and provided 8,001 to 16,000 consultations per month. One unit was open 70 hours a week, had more than 200 staff people, and provided more than 16,000 consultations per month.

Six units reported difficulties in implementing DOTS mostly due to lack of personnel to provide home visits. Eight units identified issues regarding home visits due to lack of personnel and a vehicle and violence. When DOTS patients missed their appointments, they were mostly often contacted by telephone calls, followed by home visits and certified letters.

The proportion of patients participating in DOTS in the nine local health units ranged from $25.1 \%$ to $100.0 \%$. Two units reached the treatment success target set by the Brazilian Ministry of Health $(86.3 \%$ and $88.1 \%$, respectively). The best result was seen at the unit involving CHWs, which is the community reference service for DOTS program. As for default, the 5.0\% target was not reached by any of the local health units, and only three showed rates below $10.0 \%$.

Of the 4,598 TB treatments assessed in all 32 local health units participating in TCP, $1,118(24.3 \%)$ were supervised (815 DOTS alone and 303 DOTS with CHWs) and 3,480 (75.7\%) were self-administered (SAT).

The assessment of factors associated with DOTS or SAT showed that the former was more often provided to patients younger than 50 , TB relapse and prior history of default or treatment failure. Statistically significant negative relationships were found between DOTS and unknown sputum smear result, inadequate treatment regimen, and positive or unknown HIV status. High rates of unknown sputum smear results (overall, 31.6\%; DOTS, 25.4\%; SAT, 33.6\%) and HIV status (overall, 62.7\%; DOTS, 44.0\%; SAT, 68.7\%) were major indicators of TB care.

Table 1 shows bivariate analyses of TB treatment outcomes and patient characteristics, as well as health care indicators. Of all treatments studied, 48 (1.0\%) lacked information on reason for discharge.

Table 2 shows the results of the multinomial model designed to identifying factors associated with TB treatment outcomes.

Patients who defaulted treatment were more likely to be younger (less than 30 years old; reference category: 30-49 years old), male, have positive or unknown sputum smear, pulmonary TB, positive or unknown HIV status, and receive treatment for relapse or previous default. Older patients (50-59 and $\geq 60$ years old; reference category: 30-49 years old) with normal X-ray, receiving DOTS alone, and DOTS plus CHWs were less likely to default treatment. There was found a $21.0 \%$ reduction in the likelihood of default among patients on DOTS compared to those on SAT and a $64.0 \%$ reduction among those patients monitored by CHWs.

Positive associations were found between death and age, male gender, previous default, and positive or unknown HIV status. Death rates were also 52.0\% higher among patients on DOTS compared to SAT. Death (versus cure) rates were lower among younger patients and those with positive sputum smear. Follow-up with $\mathrm{CHWs}$ also showed a statistically borderline protective effect.

Treatment failure was higher among older patients (50-59 and $\geq 60$ years), those with positive sputum smear, in treatment due to relapse or previous default or failure and those on DOTS. Failure rates were lower among patients with normal chest X-ray.

Unknown outcome was more commonly seen among patients with previous failure, inadequate treatment regimen, and positive HIV status, and less often seen among patients with normal X-ray and those monitored by CHWs. 
Table 1. Bivariate analyses comparing reason for patient discharge and potential explanatory variables. City of Rio de Janeiro, Southeastern Brazil, 2004.

\begin{tabular}{|c|c|c|c|c|c|c|c|c|c|c|c|c|c|}
\hline \multirow[t]{2}{*}{ Variable } & \multirow[t]{2}{*}{$\mathrm{n}$} & \multirow[t]{2}{*}{$\%$} & \multicolumn{2}{|c|}{$\begin{array}{c}\text { Cure } \\
(n=3,488)\end{array}$} & \multicolumn{2}{|c|}{$\begin{array}{c}\text { Default } \\
(\mathrm{n}=828)\end{array}$} & \multicolumn{2}{|c|}{$\begin{array}{l}\text { Death } \\
(n=181)\end{array}$} & \multicolumn{2}{|c|}{$\begin{array}{l}\text { Failure } \\
(n=53)\end{array}$} & \multicolumn{2}{|c|}{$\begin{array}{l}\text { Unknown } \\
\qquad(\mathrm{n}=48)\end{array}$} & \multirow{2}{*}{$\begin{array}{c}\chi^{2} \\
\text { (p-value) }\end{array}$} \\
\hline & & & $\mathrm{n}$ & $\%$ & $\mathrm{n}$ & $\%$ & $\mathrm{n}$ & $\%$ & $\mathrm{n}$ & $\%$ & $\mathrm{n}$ & $\%$ & \\
\hline Age (years) & & & & & & & & & & & & & $<0.0001$ \\
\hline$<30$ & 1,577 & 34.3 & 1,201 & 34.4 & 339 & 40.9 & 14 & 7.7 & 15 & 28.3 & 8 & 16.7 & \\
\hline 30 to 49 & 1,901 & 41.3 & 1,429 & 41.0 & 368 & 44.4 & 63 & 34.8 & 18 & 34.0 & 23 & 47.9 & \\
\hline 50 to 59 & 584 & 12.7 & 465 & 13.3 & 59 & 7.1 & 42 & 23.2 & 11 & 20.7 & 7 & 14.6 & \\
\hline$\geq 60$ & 515 & 11.2 & 381 & 10.9 & 56 & 6.8 & 60 & 33.2 & 9 & 17.0 & 9 & 18.7 & \\
\hline Unknown & 21 & 0.5 & 12 & 0.4 & 6 & 0.7 & 2 & 1.1 & 0 & 0.0 & 1 & 2.1 & \\
\hline Gender & & & & & & & & & & & & & $<0.0001$ \\
\hline Male & 2,955 & 64.3 & 2,143 & 61.4 & 599 & 72.3 & 139 & 76.8 & 39 & 73.6 & 35 & 72.9 & \\
\hline Female & 1643 & 35.7 & 1,345 & 38.6 & 229 & 27.7 & 42 & 23.2 & 14 & 26.4 & 13 & 27.1 & \\
\hline Sputum smear & & & & & & & & & & & & & $<0.0001$ \\
\hline Positive & 2,331 & 50.7 & 1,804 & 51.7 & 400 & 48.3 & 64 & 35.3 & 42 & 79.3 & 21 & 43.7 & \\
\hline Negative & 815 & 17.7 & 645 & 18.5 & 113 & 13.7 & 45 & 24.9 & 5 & 9.4 & 7 & 14.6 & \\
\hline Unknown & 1,452 & 31.6 & 1,039 & 29.8 & 315 & 38.0 & 72 & 39.8 & 6 & 11.3 & 20 & 41.7 & \\
\hline X-ray & & & & & & & & & & & & & $<0.0001$ \\
\hline Abnormal & 4,210 & 91.5 & 3,190 & 91.5 & 762 & 92.0 & 164 & 90.6 & 49 & 92.5 & 45 & 93.8 & \\
\hline Normal & 113 & 2.5 & 102 & 2.9 & 7 & 0.9 & 4 & 2.2 & 0 & 0.0 & 0 & 0.0 & \\
\hline Unknown & 275 & 6.0 & 196 & 5.6 & 59 & 7.1 & 13 & 7.2 & 4 & 7.5 & 3 & 6.2 & \\
\hline Pulmonary form & & & & & & & & & & & & & $<0.0001$ \\
\hline Yes & 4,015 & 87.3 & 3,005 & 86.1 & 764 & 92.3 & 154 & 85.1 & 52 & 98.1 & 40 & 83.3 & \\
\hline No & 583 & 12.7 & 483 & 13.9 & 64 & 7.7 & 27 & 14.9 & 1 & 1.9 & 8 & 16.7 & \\
\hline Type of treatment & & & & & & & & & & & & & $<0.0001$ \\
\hline Initial & 3,937 & 85.6 & 3,095 & 88.7 & 630 & 76.1 & 143 & 79.0 & 32 & 60.4 & 37 & 77.1 & \\
\hline Relapse & 352 & 7.7 & 259 & 7.4 & 62 & 7.5 & 19 & 10.5 & 9 & 17.0 & 3 & 6.3 & \\
\hline Previous default & 282 & 6.1 & 118 & 3.4 & 134 & 16.2 & 17 & 9.4 & 8 & 15.1 & 5 & 10.4 & \\
\hline Previous failure & 29 & 0.6 & 16 & 0.5 & 2 & 0.2 & 2 & 1.1 & 4 & 7.5 & 3 & 6.3 & \\
\hline Treatment regimen & & & & & & & & & & & & & $<0.0001$ \\
\hline Inadequate & 202 & 4.4 & 132 & 3.8 & 52 & 6.3 & 9 & 5.0 & 3 & 5.7 & 6 & 12.5 & \\
\hline Adequate & 4,396 & 95.6 & 3,356 & 96.2 & 776 & 93.7 & 172 & 95.0 & 50 & 94.3 & 42 & 87.5 & \\
\hline HIV test & & & & & & & & & & & & & $<0.0001$ \\
\hline Positive & 316 & 6.9 & 201 & 5.8 & 72 & 8.7 & 30 & 16.6 & 3 & 5.6 & 10 & 20.8 & \\
\hline Negative & 1,399 & 30.4 & 1,223 & 35.0 & 120 & 14.5 & 18 & 9.9 & 25 & 47.2 & 13 & 27.1 & \\
\hline Unknown & 2,883 & 62.7 & 2,064 & 59.2 & 636 & 76.8 & 133 & 73.5 & 25 & 47.2 & 25 & 52.1 & \\
\hline DOTS & & & & & & & & & & & & & $<0.0001$ \\
\hline Yes & 1,118 & 24.3 & 900 & 25.8 & 143 & 17.3 & 44 & 24.3 & 23 & 43.4 & 8 & 16.7 & \\
\hline No & 3,480 & 75.7 & 2,588 & 74.2 & 685 & 82.7 & 137 & 75.7 & 30 & 56.6 & 40 & 83.3 & \\
\hline Community Health $\mathrm{V}$ & r Progra & & & & & & & & & & & & $<0.0001$ \\
\hline Yes & 303 & 6.6 & 279 & 8.0 & 15 & 1.8 & 3 & 1.7 & 6 & 11.3 & 0 & 0.0 & \\
\hline No & 4,295 & 93.4 & 3,209 & 92.0 & 813 & 98.2 & 178 & 98.3 & 47 & 88.7 & 48 & 100.0 & \\
\hline
\end{tabular}




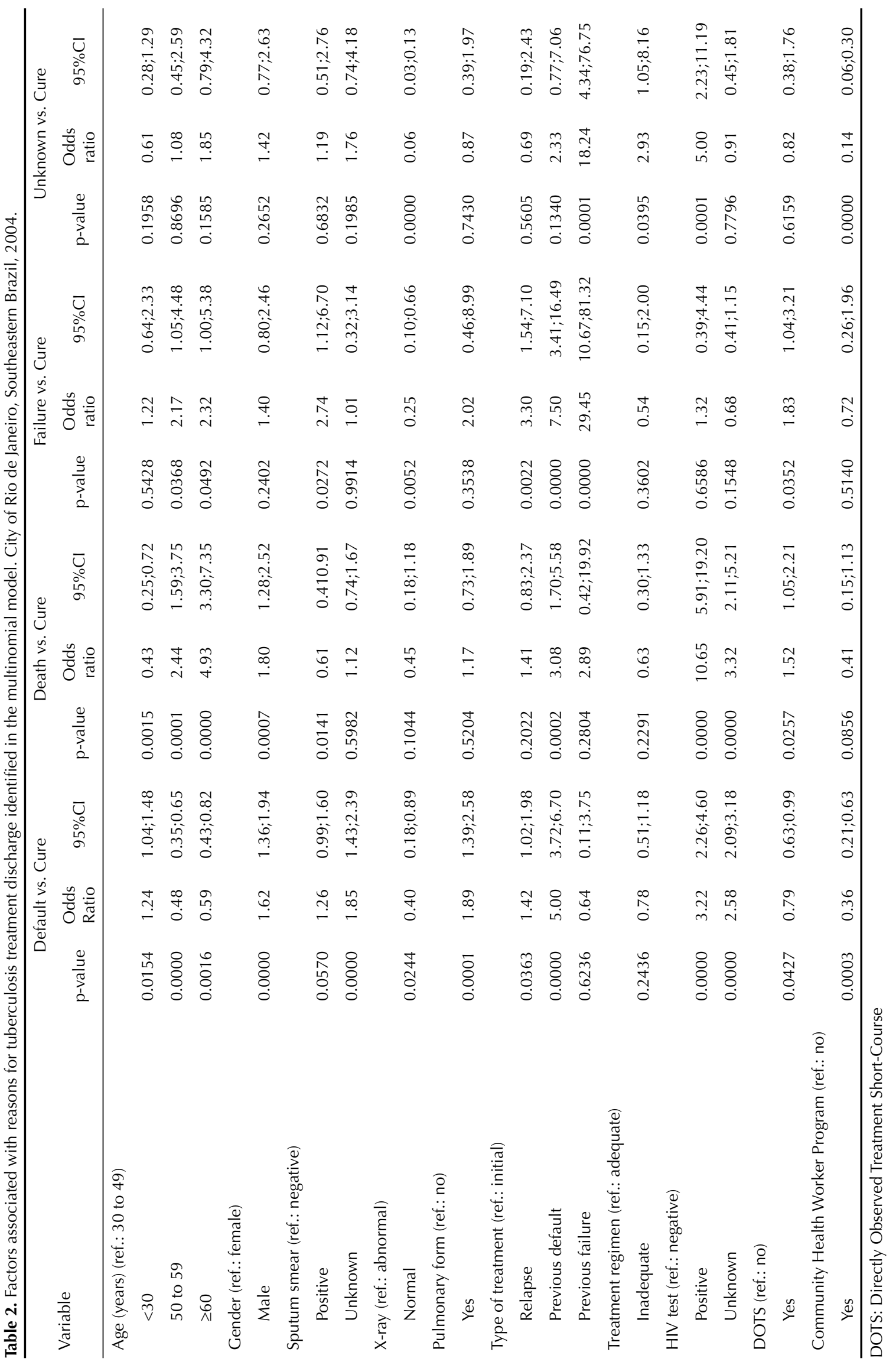




\section{DISCUSSION}

DOTS coverage in the city of Rio de Janeiro City was $24.3 \%$ in 2004. It was evidenced patient selection, despite recommendations for DOTS exclusive implementation in the context of high TB incidence, as well as to avoid patient selection biased by risk factors. ${ }^{5,10,22}$ There was a high proportion of young patients in relapse or with a history of default or previous failure in the DOTS group. This may indicate that health care services tend to prioritize DOTS for potentially noncompliant patients. A similar finding was reported in early DOTS implantation in the city of São José do Rio Preto, Southeastern Brazil. ${ }^{11}$

One of the primary health care with DOTS applied this strategy exclusively. This study found better health care indicators in DOTS than SAT patients. Although there were improvements associated with DOTS, the rates of unknown sputum smear and HIV status are high in a context where these tests are available. It may suggest low adherence to treatment guidelines affecting the course of treatment and disease.

The difference found between DOTS and SAT patients is not expressive, which is consistent with some studies of programs where DOTS is not exclusive. ${ }^{14,19}$ Better outcomes were identified, however, when DOTS was provided together with the CHW Program, a strategy that allows for tailored case management. ${ }^{4,15}$ The strategy relying on CHW as enablers for keeping patients on treatment and thus achieving higher treatment success rates should be considered as a way of organizing health care delivery and improving accessibility - two major components of DOTS.

Default is a known major barrier to more effective treatment. In addition to the lack of incentives and enablers, difficult treatment access, poor communication between health providers and patients, poor application of directly observed therapy, lack of an active search strategy for missing patients, and limitations of supervision in treatment units are all barriers to treatment success in patients under DOTS. ${ }^{23}$

Higher rates of deaths among patients under DOTS were also reported in the city of São José do Rio Preto, ${ }^{11}$ and it probably reflects the selection of patients with less favorable social and clinical conditions, not properly adjusted for in the model due to the lack of variables in the database. Additionally, the occurrence of deaths also varies depending on prior clinical history of patient, a finding that was also reported in a hyperendemic TB area in the state of São Paulo. ${ }^{7}$ Death was the outcome in $3.6 \%, 5.4 \%, 6.0 \%$, and $6.9 \%$ of those in initial treatment, with disease relapse, previous default, and previous failure, respectively, in the population studied.
With progressive implementation of DOTS in primary care units, TCP in Rio de Janeiro has improved TB care, but the goals were not achieved yet. The challenges is to evaluate and review DOTS implementation model taking into consideration context peculiarities as well as innovative strategies of health care organization and management.

The use of retrospective secondary data allowed to incorporating population data at the patient individual level and raised issues concerning cost-effective data quality control. TB treatment information flow is slow and frequently incomplete, especially concerning outcomes. ${ }^{1,17}$

DOTS was not implanted in all primary care units under TCP managed by Rio de Janeiro Health Department at the time of this study, which could have potentially introduced a bias in the study. Health units with DOTS were located in almost all Rio de Janeiro Planning Areas (APs) with different $\mathrm{TB}$ incidence rates and sociodemographic profiles. However, we cannot assure that the subset of units with DOTS is a random sample of all units.

Data about the structure and health care processes in primary care units could affect treatment results obtained. The interviews with health care teams focused on the nine units with DOTS to characterize DOTS implementation. Hierarchical modeling factors at health care unit level that could provide more information on factors at the patient level for explaining treatment outcome variation were not considered. Data collected concerning the units with DOTS showed relative homogeneity, probably because of DOTS implementation package.

In addition, differences between the number of patients reported in the study and those reported in the TB surveillance system of Rio de Janeiro City Health Department in the same period are due to the nature of the surveillance system and the focus of the study. This study focuses only on patients treated at primary health care units directly managed by the Health Department of Rio de Janeiro City. Many other federal and state health units report cases to the municipal surveillance system, but that treatment outcomes information have a delay of about one year to be included in the system.

It is important to increment DOTS coverage, emphasizing strategies that can enable health services to actively reach patients. In the city of Rio de Janeiro, there are special challenges regarding local conditions, either related to health services or the population's living conditions and violent environment. It is necessary to implement other strategies for organizing, coordinating and managing health care, including continuous education for health providers based on clinical guidelines; direct supervision of health providers; establishment of goals and regular 
monitoring of process and result indicators; and incentives for effective use of recommended guidelines. The search for continuous quality improvement in health care requires the use of multifaceted and systemic strategies in such a way that their interactions can facilitate the achievement of desirable results.

\section{REFERENCES}

1. Bierrenbach AL, Gomes ABF, Noronha EF, Souza MFM. Tuberculosis incidence and cure rates, Brazil, 20002004. Rev Saude Publica. 2007;41 (Suppl 1):24-33. DOI:10.1590/S0034-89102007000800005

2. Burman WJ, Dalton CB, Cohn DL, Butler JR, Reves RR. A cost-effectiveness analysis of directly observed therapy vs self-administered therapy for treatment of tuberculosis. Chest. 1997;112(1):63-70. DOI:10.1378/ chest.112.1.63

3. Castelo Filho A, Kritski AL, Barreto AW, Lemos ACM, Netto AR, Guimarães CA. II Consenso Brasileiro de Tuberculose: Diretrizes Brasileiras para Tuberculose 2004. J Bras Pneumol. 2004;30 (Suppl 1):S1-56. DOI:10.1590/S1806-37132004000700002

4. Cavalcante SC, Soares EC, Pacheco AG, Chaisson RE, Durovni B. Community DOT for tuberculosis in a Brazilian favela: comparison with a clinic model. Int J Tuberc Lung Dis. 2007;11(5):544-9.

5. Chaulk CP, Friedman M, Dunning R. Modeling the epidemiology and economics of directly observed therapy in Baltimore. Int J Tuberc Lung Dis. 2000;4(3):201-7.

6. Chunhaswasdikul B, Kamolratanakul P, Jittinandana A, Tangcharoensathien V, Kuptawintu S, Pantumabamrung P. Anti-tuberculosis programs in Thailand: a cost analysis. Southeast Asian I Trop Med Public Health. 1992;23(2):195-9.

7. Coelho AGV, Zamarioli LA, Perandones CA, Cuntiere I, Waldman EA. Características da tuberculose pulmonar em área hiperendêmica: município de Santos (SP). J Bras Pneumol. 2009;35(10):998-1007. DOI:10.1590/ S1806-37132009001000009

8. Desvarieux M, Hyppolite PR, Johnson WD Jr, Pape JW. A novel approach to directly observed therapy for tuberculosis in an HIV-endemic area. Am J Public Health. 2001;91(1):138-41.

9. Fryatt RJ. Review of published cost-effectiveness studies on tuberculosis treatment programmes. Int J Tuberc Lung Dis. 1997;1(2):101-9.

10. Fujiwara PI, Larkin C, Frieden TR. Directly observed therapy in New York City: history, implementation, results, and challenges. Clin Chest Med. 1997; 18(1):135-48. DOI:10.1016/S0272-5231(05)70363-4

11. Gazetta CE, Vendramini SHF, Ruffino-Netto A, Oliveira MRC, Villa TCS. Estudo descritivo sobre a implantação da estratégia de tratamento de curta duração diretamente observado no controle da tuberculose em São José do Rio Preto e seus impactos (1998-2003). J Bras Pneumol. 2007;33(2):192-8. DOI:10.1590/S180637132007000200014

\section{ACKNOWLEDGMENTS}

The authors wish to thank the coordinator of the Tuberculosis Control Program of Rio de Janeiro, the managers of local health centers, and the members of DOTS teams for providing data.
12. Gelband H. Regimens of less than six months for treating tuberculosis. Cochrane Database Syst Rev. 2000;(2):CD001362. DOI:10.1002/14651858. CD001362

13. Gourevitch MN, Alcabes P, Wasserman WC, Arno PS. Cost-effectiveness of directly observed chemoprophylaxis of tuberculosis among drug users at high risk for tuberculosis. Int J Tuberc Lung Dis. 1998;2(7):531-40.

14. Juan G, Lloret $T$, Perez C, Lopez P, Navarro R, Ramon $M$, et al. Directly observed treatment for tuberculosis in pharmacies compared with self-administered therapy in Spain. Int J Tuberc Lung Dis. 2006;10(2):215-21.

15. Mangura B, Napolitano E, Passannante M, Sarrel M, McDonald R, Galanowsky K, et al. Directly observed therapy (DOT) is not the entire answer: an operational cohort analysis. Int J Tuberc Lung Dis. 2002;6(8):65461.

16. Mwandumba HC, Squire SB. Fully intermittent dosing with drugs for treating tuberculosis in adults. Cochrane Database Syst Rev. 2001;(4):CD000970. DOI:10.1002/14651858.CD00097

17. Nogueira JA, Sá LD, França UM, Almeida SA, Lima DS, Figueiredo TMRM, Villa TCS. O sistema de informação e o controle da tuberculose nos municípios prioritários da Paraíba - Brasil. Rev EsC Enferm USP. 2009;43(1):125-31. DOI:10.1590/S008062342009000100016

18. Palmer CS, Miller B, Halpern MT, Geiter LJ. A model of the cost-effectiveness of directly observed therapy for treatment of tuberculosis. J Public Health Manag Pract. 1998;4(3):1-13.

19. Pungrassami P, Johnsen SP, Chongsuvivatwong V, Olsen J. Has directly observed treatment improved outcomes for patients with tuberculosis in southern Thailand? Trop Med Int Health. 2001;7(3):271-9. DOI:10.1046/j.1365-3156.2002.00849

20. Smieja MJ, Marchetti CA, Cook DJ, Smaill FM. Isoniazid for preventing tuberculosis in non-HIV infected persons. Cochrane Database Syst Rev. 2000;(2):CD001363. DOI:10.1002/14651858. CD001363

21. Snyder DC, Chin DP. Cost-effectiveness analysis of directly observed therapy for patients with tuberculosis at low risk for treatment default. Am J Respir Crit Care Med. 1999;160(2):582-6.

22. Suárez PG, Watt CJ, Alarcón E, Portocarrero J, Zavala D, Canales R, et al. The dynamics of tuberculosis in response to 10 years of intensive control effort in Peru. J Infectious Dis. 2001;184(4):473-8. DOI: $10.1086 / 322777$ 
23. Thiam S, LeFevre AM, Hane F, Ndiaye A, Ba F, Fielding $\mathrm{KL}$, et al. Effectiveness of strategy to improve adherence to tuberculosis treatment in a resourcepoor setting. JAMA. 2007;297(4):380-6. DOI:10.1001/ jama.297.4.380

24. Volmink J, Garner P. Directly observed therapy for treating tuberculosis. Cochrane Database Syst Rev.
2003;(1):CD003343. DOI:10.1002/14651858.

CD003343

25. Weis SE, Foresman B, Matty KJ, Brown A, Blais FX, Burgess $G$, et al. Treatment costs of directly observed therapy and traditional therapy for Mycobacterium tuberculosis: a comparative analysis. Int J Tuberc Lung Dis. 1999;3(11):976-84.

The study was funded by the Science and Technology Department of the Brazilian Ministry of Health (DECIT/MS) and the Brazilian National Committee for Technological and Scientific Development (CNPq) (403431/2004-2).

Study presented at the VII Congresso Brasileiro de Epidemiologia and XVIII IEA World Congress of Epidemiology, held in Porto Alegre, 2009.

The authors declare that there are no conflicts of interest. 